\title{
Salvadoran fathers' attendance at prenatal care, delivery, and postpartum care
}

\author{
Marion W. Carter ${ }^{1}$ and llene Speizer ${ }^{2}$
}

Suggested citation Carter MW, Speizer I. Salvadoran fathers' attendance at prenatal care, delivery, and postpartum care. Rev Panam Salud Publica. 2005;18(3):149-56.

\begin{abstract}
Objective. To provide a baseline perspective on the prevalence of Salvadoran men's attendance at prenatal care, delivery, and postpartum well-baby care and on sociodemographic factors associated with their attendance, with the goal of informing efforts to help men play more positive roles in maternal-child health.

Methods. The data came from the 2003 Salvadoran National Male Health Survey. The data focused on fathers $(\mathrm{n}=418)$ and their most recent live-born child in the preceding five years. Factors associated with the fathers' participation in prenatal care visits, attendance at delivery, and participation in postnatal well-baby visits were explored using logistic and multinomial regression models.

Results. Ninety percent of the recent Salvadoran fathers who were surveyed participated in a prenatal care visit, attended the delivery, or participated in a postpartum well-baby care visit; $34 \%$ participated in all three of the activities. Attendance at delivery was most common, reported by $81 \%$ of fathers; the most common reason that subjects cited for not attending was that they had had to work.

Conclusions. A large majority of the Salvadoran fathers participated in at least one prenatal care visit, delivery, or a postpartum well-baby care visit. While attendance alone does not necessarily indicate that men are supporting their partners, the results suggest that norms are in place for men to play positive roles in maternal-child health matters. Furthermore, the participation of fathers in these maternal and child health care activities may provide new opportunities to educate and further support men in both their own health and their family's health.
\end{abstract}

Key words Fathers; spouses; prenatal care; delivery, obstetric; postnatal care; health knowledge, attitudes, practice; El Salvador.

In recent years the role that men play in reproductive health outcomes and in maternal and child health issues has drawn increased interest. The heightened interest in both men's own reproductive health and their partici-

1 BOTUSA Project/CDC-Botswana, Gaborone, Botswana. Send correspondence to: Marion W. Carter, BOTUSA Project/CDC-Botswana, P.O. Box 90, Gaborone, Botswana; e-mail: acq0@botusa.org

2 University of North Carolina at Chapel Hill, Department of Maternal and Child Health, Chapel Hill, North Carolina, United States of America. pation in areas traditionally considered women's responsibility is the result of various factors. These include men's role in the HIV / AIDS epidemic and the wider acceptance of more complex notions of gender that highlight how relationships between men and women underpin many aspects of sexual and reproductive health (1). These and other developments have brought men's reproductive role into sharper focus and prompted efforts to better understand male reproductive health needs and "male involvement" in women's reproductive health.

To date, most of these efforts have centered on sexual and reproductive health issues such as condom use, multiple sex partners, and decisionmaking about family planning $(2,3)$. A smaller but growing area of interest is men's role in maternal and child health issues $(4,5)$, including their role in health care decisions and their re- 
sponsibilities and roles as fathers, husbands, and breadwinners. This body of work suggests that, depending on personality, individual and local circumstances, prevailing gender norms, and other factors, men can play negative or positive roles in maternal-child health behaviors and outcomes.

Men can negatively affect women's and children's health in numerous ways such as by not providing transportation or enough money for a health care visit or not following a health care provider's treatment advice. These types of harmful behaviors may be more likely where men are expected to make most household decisions or where they feel entitled to control women's movements and bodies. In documenting some of the barriers to better health that women face, researchers have identified instances in which men have engaged in such damaging conduct. Researchers have also demonstrated how women's social status relative to that of men affects women's ability to make appropriate choices in seeking health care $(6,7)$.

Yet even when men do not negatively affect women's health, program planners and policymakers are still interested in men because of the influence they can and often do have in supporting positive health behaviors within their families. Increasingly, the view that men represent only barriers to the health of other household members is being supplanted by one that recognizes that men also often play, and want to play, positive roles in household health (8). Many men are loving, caring fathers and partners and may only need to be acknowledged for the benefits they already provide to their families. This more balanced perspective on men's roles in family health care matters also facilitates a more complex understanding of why some men are not involved in these health matters. Factors contributing to such noninvolvement may include a lack of knowledge about how to help during a medical episode or an inability to take time from work.

Efforts to support men's participation in household health care activities have the aim of both improving health outcomes and promoting stronger, more equitable families $(9,10)$. Thus far, there is little evidence that increased positive male involvement improves health outcomes significantly. However, the link is intuitively appealing, and evidence to support it is growing $(7,11)$. Regardless of potential health outcomes, increased male participation in family health matters is itself worthwhile, given that better household gender relations and male support of healthy behaviors are arguably desirable outcomes in and of themselves.

Among the first steps toward helping men play more positive roles in maternal-child health is understanding the roles they currently play, and why. This will help ensure that subsequent interventions are built upon correct assumptions about men's motivation and participation. Using crosssectional, population-based data, we aim to help illuminate men's current role by examining one aspect of men's participation in maternal-child health in El Salvador. Specifically, we focus on Salvadoran men's attendance at prenatal care, delivery, and postpartum well-baby care for their most recent child born within the previous five years. The data for this study, which are population-based and nationally representative of recent fathers, come from men's reports of their own behavior, not proxy data collected from their spouses. These data provide a first glance at Salvadoran men's participation in three important aspects of maternal and child health care. A larger aim of this study is to inform efforts to support and improve male participation in maternal and child health behaviors in El Salvador and neighboring countries as well as efforts to promote "responsible fatherhood" in those nations (12).

In this study, we addressed the following research questions:

- What percentages of men participated in at least one prenatal care visit, attended the delivery of their child, or participated in at least one postpartum well-baby care visit? Among men who did not partici- pate or attend, what main reason did they give for not doing so?

- What were the characteristics of the men who were involved in each of these aspects of maternal-child health care?

- What were the characteristics of the men who were the least likely and of the men who were the most likely to be involved in these three activities?

\section{El Salvador study context}

A small country, El Salvador has a population of 6.5 million people, about $45 \%$ of whom live in rural areas. Life expectancy is relatively high $(\sim 70$ years), and $80 \%$ of the population is estimated to be literate. Nevertheless, the Salvadoran government has reported that just under half of the population lives in poverty (13), and the country is still recovering from years of civil war and strife. Also, like most countries, El Salvador is characterized by gender inequity that generally favors men socially, economically, and politically, though progress in some areas, such as education, is evident (14).

According to 2002-2003 data, about $67 \%$ of married women aged 15 to 44 were then using a family planning method, and a similar proportion of men aged 15 to 59 were doing so (15). The most common method reported by both women and men was female sterilization (about a third), followed by injectable and oral contraceptives. The fertility rate in El Salvador has declined noticeably in recent decades, from 6.3 children per woman in the mid-1970s to 2.9 children per woman in the late 1990s. During this time the average age of Salvadoran women at first marriage rose by two years, though their age at first birth rose only slightly (15). Prenatal care and hospital deliveries are common. Of women who had live births from 1997 through $2002,86 \%$ reported receiving prenatal care. Sixty-six percent received care during the first trimester, and over $70 \%$ had at least five check-ups during their pregnancy. Sixty-nine percent of live births from 1997 through 2002 oc- 
curred in a hospital, and the national cesarean rate for the early 2000s was estimated at $22 \%$ (15).

\section{METHODS}

The data for this study came from the El Salvador National Male Health Survey (Encuesta Nacional de Salud Masculina), carried out in 2003 by the Salvadoran Demographic Association (Asociación Demográfica Salvadoreña), with technical assistance from the United States Centers for Disease Control and Prevention. The first male survey of its kind in El Salvador, it collected data from 1315 respondents, reflecting an $80 \%$ response rate among the 1650 households approached that had eligible men living there. The survey used a multistage sampling design, in which potential participants were first stratified by general area of residence (Metropolitan Area of San Salvador, other urban, and rural) and by neighborhood blocks. Then, households within blocks were randomly selected. One resident male aged 15 to 59 was then randomly selected from each household for a face-to-face interview with a male interviewer. The data were weighted to represent the reproductive-age male population of El Salvador. All estimates presented in this paper were adjusted with sampling weights to account for the sampling design and were derived with the use of Stata version 8.2 software (StataCorp, College Station, Texas, United States of America).

Men who reported having fathered at least one live-born child in the five years preceding the survey $(32 \%$ of all respondents, $n=425$ ) were asked questions about their participation in prenatal and postnatal care and in the delivery of their child, as well as questions about the child and the pregnancy (e.g., sex of child, date of birth, intentionality of pregnancy (according to the man), place of birth). Specifically, respondents were asked whether they participated in (asistió) any prenatal care visit during pregnancy, whether they attended or were waiting at (estaba pendiente) the place of deliv- ery, and whether they participated in (asistió) any postpartum well-baby care visit after delivery. The question about delivery attendance explicitly included "waiting" because of clinical regulations that commonly prohibit family members from being with women at delivery. Respondents who said they did not participate in or attend any of the three birth-related health care activities were asked to give the main reason for not doing so.

To minimize recall bias and to avoid violating the assumption of independence of observations, the survey asked the 425 fathers all these questions only about their last live-born child within the previous five years. After several respondents were excluded because of missing data, the final sample for this analysis consisted of 418 men.

After examining the data, we recoded the variable denoting attendance at delivery. Although the question on attendance at delivery was worded in hopes that men who were waiting outside the place of delivery would respond affirmatively, 38 men said that they did not attend because they "were not admitted" to the place of delivery, which in all cases was a hospital or other clinical setting. In our analysis, we assumed that these men were waiting at the place of delivery, and we recoded their responses to indicate that they had attended the delivery.

We assessed associations between participation in the three birth-related health care activities and various characteristics of the men, their households, the pregnancy, and the child. We selected the characteristics on the basis of data availability and previous research about what may compel men to participate in these health care activities. Some variables reflect individual motivation for and knowledge about participation in maternal health care (e.g., education, relationship with mother of child, gender attitudes), and others reflect men's availability to participate or structural barriers to their participation (rural residence, occupation, child's place of birth). Other key factors, including health problems of the mother or the baby during pregnancy or delivery, other characteristics of the mother, and the availability of other sources of social support, may be associated with fathers' attendance or participation. However, we did not consider these other possible factors in our analysis because data on them were not available (16).

Many variables are general sociodemographic characteristics and thus may be associated with a number of mechanisms that affect participation. For example, educational attainment may be associated with knowledge about maternal-child health, employment status, and a man's level of comfort in heath care settings, each of which may in turn be associated with participation in the activities surveyed.

One variable that we examined was socioeconomic status. It was an unweighted count-variable, from 0 to 9 , of the respondent's household services and durable goods (number of rooms in the house, type of cooking fuel, type of toilet, water source, and whether the house had electricity, a television, a refrigerator, a telephone, and/or a vehicle). The variable was categorized into three groups: 0-3, "low"; 4-6, "medium"; and 7-9, "high." The other variables considered were: educational attainment (0-3 years, 4-6 years, 7+ years), area of residence (Metropolitan Area of San Salvador, other urban area, rural area), man's age around the time of pregnancy (15-24, 25-34, 35-44, 45-59 years old), the child's birth order (first birth vs. higher order), the man's relationship to the child's mother around the time of the pregnancy (married/consensual union vs. other relationship such as dating or friendship), and the intentionality of the pregnancy according to the man (mistimed, unwanted, intended). We also examined the men's occupation at the time of the interview; during data analysis their responses were grouped into broad categories according to official Salvadoran job codes.

We also included a measure of a man's attitudes about male authority, which was based on his response to two statements about household gender relations: (1) "For household decisions, the man has the last word" and (2) "Even if she doesn't want to, the 
wife ought to accept the orders of her husband in order to maintain family unity." Men who agreed with both statements were categorized as having a high male-authority attitude. Place of birth of the child (home birth vs. medical facility) was included in the analysis of attendance at delivery, and the sex of the child was included in the analysis of participation in postpartum well-baby care visits.

In addition to describing the sample and the patterns in the men's participation in birth-related health care activities, we ran separate multivariate logistic regression models to evaluate independent predictors of their participation in these activities. We also conducted multinomial logistic regression analyses of how many of the three activities the men reported participating in (none of the activities, one or two, or all three). In all the analytical models, we excluded the subjects' socioeconomic status because it was highly correlated with education level and area of residence. We also excluded religion because it added little to any model.

\section{RESULTS}

Table 1 describes the sample of recent fathers and their most recent liveborn child. Most of the fathers were under 35 when their last child was born, and $92 \%$ were married or in a consensual union with their partner at the time of pregnancy. About half lived in rural areas, and a third reported working in agriculture. Their educational level was low, with $76 \%$ having six years or less of schooling. Seventyfive percent of the recent pregnancies that ended in live birth were intended, and $10 \%$ were unwanted. About a third of recent fathers agreed with the two statements about male household authority and thus were categorized as having high husband-authority attitudes. Reflecting both urbanization and medicalization of birth in El Salvador, $72 \%$ of deliveries were in a medical setting, usually a hospital.

Table 2 presents the information on the men's reports about whether they participated in a prenatal care visit, at-
TABLE 1. Demographic profile of Salvadoran fathers and their child born most recently in preceding five years $(n=418)$

\begin{tabular}{|c|c|}
\hline Characteristic & $\begin{array}{l}\text { Weighted } \\
\text { percentage }\end{array}$ \\
\hline \multicolumn{2}{|l|}{ Age (yr) } \\
\hline $15-24$ & 29 \\
\hline $25-34$ & 38 \\
\hline $35-44$ & 25 \\
\hline $45-59$ & 7 \\
\hline \multicolumn{2}{|l|}{ Area of residence } \\
\hline San Salvador Metropolitan Area & 19 \\
\hline Other urban & 29 \\
\hline Rural & 51 \\
\hline \multicolumn{2}{|l|}{ Socioeconomic status ${ }^{b}$} \\
\hline Low (0-3) & 41 \\
\hline Medium (4-6) & 35 \\
\hline High (7-9) & 24 \\
\hline \multicolumn{2}{|l|}{ Educational attainment } \\
\hline $0-3$ years & 24 \\
\hline $4-6$ years & 52 \\
\hline $7-12$ years & 15 \\
\hline $13+$ years & 9 \\
\hline \multicolumn{2}{|l|}{ Occupational category } \\
\hline White collar & 17 \\
\hline Blue collar & 34 \\
\hline Agriculture & 31 \\
\hline Unemployed & 11 \\
\hline Unclassified/no response & 7 \\
\hline \multicolumn{2}{|l|}{$\begin{array}{l}\text { Relationship to partner around the } \\
\text { time of birth }\end{array}$} \\
\hline Married/consensual union & 92 \\
\hline Other relationship & 8 \\
\hline \multicolumn{2}{|l|}{ Birth order of last child } \\
\hline First & 26 \\
\hline Second & 21 \\
\hline Third & 18 \\
\hline Fourth+ & 35 \\
\hline \multicolumn{2}{|l|}{ Pregnancy intention } \\
\hline Intended & 75 \\
\hline Mistimed & 13 \\
\hline Unwanted & 10 \\
\hline Don't know/No response & 2 \\
\hline \multicolumn{2}{|l|}{ Place of child's birth } \\
\hline Home & 28 \\
\hline Medical facility or other & 72 \\
\hline \multicolumn{2}{|l|}{ Husband authority attitudes ${ }^{c}$} \\
\hline High & 31 \\
\hline Medium or low & 69 \\
\hline \multicolumn{2}{|l|}{ Sex of child } \\
\hline Female & 45 \\
\hline Male & 55 \\
\hline
\end{tabular}

a The percentages are weighted to reflect reproductive-age males in El Salvador.

b Socioeconomic status is based on a scale of nine household goods and services.

c The husband authority attitudes level is based on answers to two gender attitude questions.

tended the delivery, or participated in a postpartum well-baby care visit. For each of the three activities, over half of the men reported participating or attending. The percentage was highest
TABLE 2. Weighted percentage of Salvadoran fathers who attended prenatal care, delivery, or postpartum care for the last child born in the preceding five years $(n=418)$

\begin{tabular}{lr}
\hline & $\begin{array}{r}\text { Weighted } \\
\text { percentage }\end{array}$ \\
\hline Activity attended & \\
Any prenatal care visit & 57.1 \\
Delivery & 81.4 \\
Any well-baby care visit & 60.8 \\
& \\
Number of the three activities that & \\
the fathers attended & \\
$\quad$ None & 9.7 \\
$\quad$ One or two & 56.1 \\
$\quad$ All three & 34.1 \\
At least one & 90.3 \\
\hline
\end{tabular}

a The percentages are weighted to reflect reproductive-age males in El Salvador.

for delivery attendance, $81 \%$. Among men who did not report these three behaviors, "had to work" (tenía que trabajar) was the most commonly cited reason for not doing so. This reason was noted by somewhat over $80 \%$ of both the men who did not attend any prenatal care and the men who did not attend a well-baby care visit, and just under $70 \%$ of the men who did not attend delivery (data not shown). The next most common reason given was that he was not living with the mother of his child $(6.2 \%$ of men who did not attend prenatal care and $10.5 \%$ of men who were not at delivery). A few respondents provided such other reasons as that the woman did not want him to go or that it was not something that men do. Some other individual responses included: "I don't like that," in reference to a prenatal care visit; "The birth came so suddenly I couldn't make it," in reference to delivery attendance; and "We didn't talk about it" and "I had to take care of the other children," in reference to a postpartum care visit.

We also examined the men's level of participation by determining how many of the three activities men reported participating in. A small minority $(9.7 \%)$ of the men did not participate in a prenatal care visit, attend the delivery, or participate in a postpartum well-baby care visit. Somewhat over half $(56.1 \%)$ participated in or attended one or two of the three. Among 
those who attended two, no single combination (e.g., prenatal care + delivery) was clearly dominant. A third of the men $(34.1 \%)$ reported participating in or attending all three.

The results from logistic regressions of whether men reported these three behaviors are shown in Table 3. Pregnancy intention was an important predictor of participation. Men with an unwanted or mistimed pregnancy were significantly less likely than their counterparts with an intended pregnancy to attend prenatal or postpartum care. The analysis of delivery attendance found that men who reported an unwanted pregnancy were less likely to attend the delivery than were men with an intended pregnancy. Notably, men with a mistimed pregnancy were more likely than men with an intended pregnancy to attend delivery, but the difference was not statistically significant. When we used an alternative measure of pregnancy intention in these models, namely whether men reported being happy upon learning about that pregnancy, we found that men who said they felt happy were more likely to attend the delivery than were men who said they were not happy (model not shown).

Men who were married or in a consensual union with their partner at the time of pregnancy were more likely than men in other relationships to report attending delivery and participating in prenatal and well-baby visits. Men with seven or more years of education were more likely to participate in prenatal and well-baby visits than were men with little or no formal education. Conversely, education level was not associated with delivery attendance.

In terms of residence, men living in rural areas were about half as likely as men in urban areas to participate in prenatal care, after controlling for other characteristics. The results for rural residence in the analyses of delivery and postpartum attendance were nonsignificant. Finally, the associations that prenatal care participation, well-baby care participation, and attendance at delivery had with the other factors were mostly nonsignificant. These included male authority

TABLE 3. Association of various factors with Salvadoran fathers' attendance at prenatal care, delivery, and postpartum well-baby care for their most recent live born child within the previous five years, as determined by multivariate logistic regression $(n=418)^{a}$

\begin{tabular}{|c|c|c|c|c|c|c|}
\hline \multirow[b]{2}{*}{ Factor } & \multicolumn{2}{|c|}{ Prenatal care } & \multicolumn{2}{|c|}{ Delivery } & \multicolumn{2}{|c|}{$\begin{array}{c}\text { Postpartum } \\
\text { well-baby care }\end{array}$} \\
\hline & Odds ratio & $P$ & Odds ratio & $P$ & Odds ratio & $P$ \\
\hline \multicolumn{7}{|l|}{ Pregnancy intention } \\
\hline Intended & 1.00 & - & 1.00 & - & 1.00 & - \\
\hline Mistimed & 0.40 & $<0.05$ & 2.16 & 0.08 & 0.51 & $<0.05$ \\
\hline Unwanted & 0.13 & $<0.01$ & 0.45 & $<0.05$ & 0.27 & $<0.01$ \\
\hline \multicolumn{7}{|l|}{ Birth order } \\
\hline First birth & 0.79 & 0.49 & 0.66 & 0.31 & 1.95 & 0.10 \\
\hline Second+ birth & 1.00 & - & 1.00 & - & 1.00 & - \\
\hline \multicolumn{7}{|l|}{ Education } \\
\hline $0-3$ years & 1.00 & - & 1.00 & - & 1.00 & - \\
\hline $4-6$ years & 1.05 & 0.89 & 0.56 & 0.24 & 1.34 & 0.31 \\
\hline $7+$ years & 3.54 & $<0.01$ & 0.83 & 0.75 & 2.81 & $<0.01$ \\
\hline \multicolumn{7}{|l|}{ Father's age } \\
\hline $15-24$ & 0.59 & 0.11 & 1.10 & 0.83 & 0.71 & 0.37 \\
\hline $25-34$ & 1.00 & - & 1.00 & - & 1.00 & - \\
\hline $35-44$ & 0.62 & 0.13 & 0.59 & 0.19 & 1.05 & 0.88 \\
\hline $45-59$ & 2.99 & 0.09 & 0.49 & 0.28 & 1.16 & 0.82 \\
\hline \multicolumn{7}{|l|}{ Relation to partner } \\
\hline Other relation & 1.00 & - & 1.00 & - & 1.00 & - \\
\hline Married/consensual union & 2.27 & $<0.05$ & 3.49 & $<0.05$ & 2.95 & $<0.01$ \\
\hline \multicolumn{7}{|l|}{ Area of residence } \\
\hline Urban & 1.00 & - & 1.00 & - & 1.00 & - \\
\hline Rural & 0.52 & $<0.05$ & 0.89 & 0.76 & 0.71 & 0.22 \\
\hline \multicolumn{7}{|l|}{ Male authority attitude } \\
\hline Low or medium & 1.00 & - & 1.00 & - & 1.00 & - \\
\hline High & 0.83 & 0.49 & 0.80 & 0.57 & 0.92 & 0.78 \\
\hline \multicolumn{7}{|l|}{ Place of birth } \\
\hline Medical facility/Other & $N A^{b}$ & NA & 1.00 & - & NA & NA \\
\hline Home & NA & NA & 1.22 & 0.59 & NA & NA \\
\hline \multicolumn{7}{|l|}{ Sex of child } \\
\hline Boy & NA & NA & NA & NA & 1.00 & - \\
\hline Girl & NA & NA & NA & NA & 0.89 & 0.68 \\
\hline
\end{tabular}

a The results are expressed as odds ratios, which are exponentiated coefficients from the multivariate logistic regression.

${ }^{b} \mathrm{NA}=$ not applicable. With the sex of child factor, that was included in only the well-baby care visit because there was no information about whether fathers knew the sex of the child prior to delivery.

attitudes; place of birth, which was not associated with delivery attendance; birth order of the child; and the father's age around the time of birth. However, the correlation between some of these variables and participation in some activities approached statistical significance.

In our bivariate analyses we found that the number of the three birthrelated health care activities that subjects reported participating in (none, one or two, all three) was associated with the area of residence, pregnancy intention, relationship to partner, and education. The men most likely to report all three behaviors were those who lived in an urban area (49\%, vs. $30 \%$ for rural men), those with in- tended pregnancies (44\%, vs. $14 \%$ for men with unwanted pregnancies), those with more than a primary education $(55 \%$, vs. $33 \%$ for men with 0-3 years schooling), and those who were married or in a consensual union with their partner $(40 \%$, vs. $26 \%$ for men in other relationships). Men's socioeconomic status, their age around the time of pregnancy, the birth order of the child, and their male authority attitudes were not significantly associated with participation in all three activities.

The multivariate model of the number of these activities that men reported participating in further confirmed these findings. That model only included the four variables found to be significant in bivariate analyses; the re- 
sults were nearly identical when the other variables were also included. Shown in Table 4, the results indicate that pregnancy intention, education, and relationship to partner distinguished men who participated in none of the three health care activities from the men who participated in all three. In addition, the directions of the associations between these select variables and the outcome were consistent with those from the logistic regression analyses described in Table 3, thus providing a similar interpretation. Among men who participated in at least one activity, pregnancy intention and residence distinguished men who reported participating in one or two from those who reported participating in all three.

\section{DISCUSSION}

These data provide the first population-based perspective of Salvadoran men's attendance at prenatal care, delivery, and postpartum care, as reported by fathers themselves. Despite these strengths, this study was limited by various factors, including the relatively small sample size of recent fathers and the small number of covariates that were available to use in the analyses. Moreover, without much past research on male involvement in maternal-child health to guide hypothesis testing, the analyses were somewhat exploratory. Nevertheless, the results inform our understanding of Salvadoran fathers' involvement in maternal-child health care and point to ways to increase or better support their involvement.

First, the results showed that $90 \%$ of recent Salvadoran fathers reported that they had participated in a prenatal care visit, attended the delivery, or participated in a postpartum well-baby care visit; a third of the fathers reported that they did all three. Currently, there are few other data from El Salvador or other countries with which to compare these results, and to our knowledge no international targets against which to benchmark these figures.

Nevertheless, data from this survey suggest that such involvement is com-

TABLE 4. Association between select characteristics and Salvadoran fathers' participation in fewer birth-related health care activities, according to a multinomial logistic regression model $(n=418)^{a}$

\begin{tabular}{|c|c|c|c|c|}
\hline \multirow[b]{2}{*}{ Characteristic } & \multicolumn{2}{|c|}{ Partic. in 0 vs. 3 activities } & \multicolumn{2}{|c|}{ Partic. in $1-2$ vs. 3 activities } \\
\hline & Odds ratio & $P$ & Odds ratio & $P$ \\
\hline \multicolumn{5}{|l|}{ Pregnancy intention } \\
\hline Intended & 1.00 & - & 1.00 & - \\
\hline Mistimed & 1.27 & 0.67 & 1.89 & 0.09 \\
\hline Unwanted & 14.95 & $<0.01$ & 4.82 & $<0.01$ \\
\hline \multicolumn{5}{|l|}{ Education } \\
\hline $0-3$ years & 1.00 & - & 1.00 & - \\
\hline $4-6$ years & 0.78 & 0.75 & 1.16 & 0.74 \\
\hline $7+$ years & 0.10 & $<0.05$ & 0.55 & 0.24 \\
\hline \multicolumn{5}{|l|}{ Relation to partner } \\
\hline Other relation & 1.00 & - & 1.00 & - \\
\hline Married/Consensual union & 0.10 & $<0.01$ & 0.67 & 0.40 \\
\hline \multicolumn{5}{|l|}{ Area of residence } \\
\hline Urban & 1.00 & - & 1.00 & - \\
\hline Rural & 1.06 & 0.92 & 2.08 & $<0.01$ \\
\hline
\end{tabular}

mon among recent fathers and thus that social norms allow, if not support, this kind of participation by fathers in maternal-child health. This idea is further supported by the reasons men gave for not attending particular activities. Instead of citing explicit normative barriers such as "It's for women," most men said that they "had to work," a response that implicates external or structural factors. Such results may be encouraging to people working to help men play more positive roles in the health of their partners and children. The results also point to some of the barriers-both perceived and real-to men's involvement.

The results of our multivariate analyses show that men's pregnancy intention and their relationship with their partner around the time of pregnancy were both strongly associated with their participation in birth-related health care activities. Men with unwanted pregnancies and those not married to their partner were much less likely to participate in these activities than were their respective counterparts. Reporting an unwanted pregnancy and having a more casual relationship to the mother of their child may represent men's lower commitment to and interest in the mother and child. If so, these results may also indicate that such men are not involved in other aspects of these women's and children's lives. More research could determine if non-attendance at these health care activities, an unwanted pregnancy, or a casual relationship are also indicative of men who provide little or no financial or emotional support, for example. These cases could represent situations more explicitly detrimental to the mother and child.

Education also was a significant predictor in these analyses. Men with more than a primary school education were more likely than their lesseducated counterparts to participate in one or more of the birth-related activities. Possible reasons for this may be similar to those found in studies of women $(17,18)$. Educated fathers may be more likely to be of higher socioeconomic status, to have more free time or more flexible work schedules, to ascribe to norms about fatherhood that facilitate involvement in family health, or to use health care providers who facilitate their attendance at prenatal care, delivery, and well-baby care.

Similarly, rural residence was associated with a lower likelihood of men's participating in prenatal care visits (17). Moreover, men from rural areas 
were more likely to have participated in one or two of the health care activities as opposed to all three. Possible reasons for this include relatively weak health care infrastructure in rural areas, long distances between rural residences and health care facilities, and economic and labor practices in rural settings that may limit men's ability to participate in many health care activities with their partners. More research is needed to more fully explicate these and other findings.

The factors (e.g., pregnancy intention and relationship with partner) that are associated with participating in each of the three health care activities were similar. Similarly, the prevalences of men's attending prenatal care visits and of attending postpartum care visits were similar. Notably, the proportion of the fathers who attended the delivery of the last-born child was somewhat higher than were the proportions who attended prenatal and well-baby care. This difference could reflect the common notion that delivery is usually a more important and singular event, compared to prenatal and postnatal care visits. Nevertheless, this finding should not overshadow the fact that each behavior is different in practice and may have its own meaning for men and their families. For example, since women in El Salvador attend an average of more than five prenatal care visits during a pregnancy, men arguably have more opportunity to attend at least one prenatal visit than they might with well-baby care visits, which are often fewer. Thus the similarity in the reported prevalences of prenatal care attendance and well-baby care visit attendance actually may conceal differences in men's ability to and/or motivation for attending each type of visit. Thus, while there are evidently some similarities in the factors that affect men's attendance at these three activities, important differences remain among these behaviors. Recognizing and assessing these potential differences is key to developing programs aimed at better supporting men's ability to participate in and contribute to these three activities.
Fathers' participation in birthrelated health care activities is arguably in and of itself an important outcome. Men's attendance shows that women are not alone in these visits and thus may have assistance from their partner should a problem arise. Further, the attendance creates some contact between men and health care sites. In El Salvador and elsewhere, health officials are concerned that many men may feel excluded from parts of the health care system, and that the men do not attend to their own health as well as they should (19). These visits thus may provide opportunities to draw men further into the health care system, where their own health care needs can be addressed. The visits may also further educate and motivate men to play positive roles in their partner's pregnancy and in the delivery and care of their child. It is not clear from these data whether men participate in these visits fully, such as by talking directly with the provider themselves, or whether they take a more passive role, such as by waiting outside while their partners receive the care. Additional study can clarify what "attendance" at these birth-related activities entails for men, and how health care systems can best address issues related to the health of men or their family, whether in a clinic, a hospital, or even a homebased care setting.

Fathers' participation in the three birth-related health care activities examined in this analysis is also of interest because it might signify a more generalized pattern of positive, supportive participation in their family's health and in familial relationships. We did not find the subjects' male-authority attitudes to be significantly associated with their participation in health-related activities. However, our assessment of these attitudes was based on responses to only two attitude questions and so does not reflect the subjects' overall behavior or other aspects of gender relations that could be associated with such participation. Results of qualitative research from rural Guatemala suggest that fathers who participate in such birth-related health care activities generally do so out of love for the mother and/or concern about the health of the mother and child (20). The same may be true among the Salvadoran men in our study, though additional research is needed to assess this.

Of course, mere participation in birthrelated health care activities as defined in this survey is not the only way that men can contribute to maternal-child health. For example, men can also provide advice or financial and emotional support. Also, participation in birth-related health care activities does not necessarily mean that men are positively involved in maternalchild health. Similarly, a lack of participation does not necessarily indicate that men are not positively involved in maternal-child health. Studies focused on male participation in maternalchild health could do much to assess if our data on participation provide good summary indicators of positive involvement or if other measures might be more robust and indicative.

The development of such indicators and measures is important as the field of men's participation in maternalchild health grows. Given the prominent role of gender and gender relations in determining health behavior and outcomes, the increased attention to men's health and men's influence on the health of their family is unlikely to fade. This focus on men's participation should help us to better understand how individuals and families navigate the health care system, and to find new ways of addressing persistent health problems, including those associated with maternal-child health.

Acknowledgements. The authors would like to thank Lisa Whittle and Linda Bartlett for their feedback on this paper, and Steve McCracken and José Mario Cáceres for their support during survey development and data collection. This paper was completed while Marion Carter was an Epidemic Intelligence Service officer with the Division of Reproductive Health, Centers for Disease Control and Prevention, Atlanta, Georgia, United States of America. 


\section{REFERENCES}

1. Greene M, Biddlecom A. Absent and problematic men: demographic accounts of male reproductive roles. Popul Dev Rev. 2000;26: 81-115.

2. EngenderHealth. New paradigms of male participation in sexual and reproductive health: literature review. Washington, D.C.: EngenderHealth; 1998.

3. Drennan M. Reproductive health: new perspectives on men's participation. Baltimore: Johns Hopkins School of Public Health; 1998. (Population Reports. Series J, No. 46).

4. Singh K, Bloom S, Tsui A. Husbands' reproductive health knowledge, attitudes, and behavior in Uttar Pradesh, India. Stud Fam Plann. 1998;29(4):388-99.

5. Bloom S, Tsui A, Plotkin M, Basset M. What husbands in northern India know about reproductive health: correlates of knowledge about pregnancy and maternal and sexual health. J Biosoc Sci. 2000;32(2):237-51.

6. Dudgeon M, Inhorn M. Men's influence on women's reproductive health: medical anthropological perspectives. Soc Sci Med. 2004;59(7):1379-95.

7. Boender C, Santana D, Santillán D, Hardee K, Greene ME, Schuler S. The 'so what' report: a look at whether integrating a gender focus into programs makes a difference in outcomes. Washington, D.C.: Population Reference Bureau; 2004.
8. Interagency Gender Working Group. Involving men to address gender inequities: three case studies. Washington, D.C.; Population Reference Bureau; 2003.

9. Linkages-International Institute on Sustainable Development. Programme of Action of the United Nations International Conference on Population \& Development [Web site]. Available from: http://www.iisd.ca/cairo/ program/p00000.html. Accessed 29 July 2005.

10. World Health Organization, Reproductive Health and Research, Making Pregnancy Safer Initiative. Working with individuals, families and communities to improve maternal and newborn health. Geneva: WHO; 2003. (WHO/FCH/RHR/03.11)

11. Wang $C$, Wittinghoff $E$, Hua LS, Wang $H$, Rong ZM. Reducing pregnancy and induced abortion rates in China: family planning with husband participation. Am J Public Health. 1998;88(4):646-8.

12. Alatorre J. Paternidad responsable en el Istmo Centroamericano. México, D.F.: Comisión Económica para América Latina y el Caribe; 2002.

13. Pan American Health Organization. Country health profile 2002: El Salvador. Regional Core Health Data System 2003. Available from: http://www.paho.org/English/DD/AIS / cp_222.htm [Web site]. Accessed 2 June 2004.

14. World Bank. El Salvador: moving to a gender approach: issues and recommendations. Wash- ington, D.C.: World Development Sources; 1996.

15. Asociación Demográfica Salvadoreña. Encuesta Nacional de Salud Familiar: FESAL 2002/03. Informe resumido. San Salvador: ADS; 2003.

16. Carter M. Husband involvement in the treatment of child illness in Guatemala. J Biosoc Sci. 2004;36:189-208

17. AbouZahr C, Wardlaw T. Antenatal care in developing countries: promises, achievements and missed opportunities. An analysis of trends, levels, and differentials, 1990-2001. Geneva: World Health Organization and United Nations Children's Fund; 2004.

18. Hobcraft J. Women's education, child welfare, and child survival: a review of the evidence. Health Transit Rev. 1993;3(2):159-75.

19. Alan Guttmacher Institute. In their own right: addressing the reproductive health needs of men worldwide. New York: Alan Guttmacher Institute; 2003.

20. Carter M. "Because he loves $\mathrm{me}^{\text {": }}$ husbands' involvement in maternal health in Guatemala. Cult Health Sex. 2002;4(3):259-79.

Manuscript received 8 October 2004. Accepted for publication 13 May 2005.

RESUMEN Objetivo. Proporcionar información de base acerca de la frecuencia con la cual los hombres salvadoreños acuden a la atención prenatal, al parto y a la atención del bebé sano después del parto, así como acerca de los factores sociodemográficos que se asocian con su asistencia a esas actividades, a fin de orientar acciones encaminadas a ayudar a los hombres a participar de una forma más útil en la salud maternoinfantil.

La presencia de los padres salvadoreños durante la atención prenatal, el parto y la atención posparto Métodos. Los datos, que se obtuvieron de la Encuesta Nacional de Salud Masculina de 2003 (ENSM-03) de El Salvador, se centran en los padres $(n=418)$ y en el hijo más joven que haya nacido vivo durante los cinco años anteriores a la encuesta. Mediante modelos de regresión logística y multinomial se exploraron factores asociados con la presencia de los padres en las consultas prenatales, en el parto y en las consultas para la atención del neonato sano.

Resultados. Noventa por ciento de los padres salvadoreños que fueron encuestados participaron en una consulta prenatal, asistieron al parto o estuvieron en una consulta para la atención del bebé sano; $34 \%$ de ellos participaron en las tres actividades. Lo más frecuente fue la asistencia al parto, notificada por $81 \%$ de los padres, y la razón dada con mayor frecuencia para no haber asistido fue la necesidad de ir a trabajar.

Conclusiones. La gran mayoría de los padres salvadoreños habían estado en por lo menos una consulta prenatal, en el parto o en una consulta para la atención del bebé sano. Aunque la participación en estas actividades no necesariamente significa que los cónyuges les estén dando a sus parejas el apoyo debido, los resultados parecieran indicar que ya están sentadas ciertas normas para que los hombres puedan desempeñar un papel positivo en el área de la salud maternoinfantil. Además, la participación de los padres en estas actividades relacionadas con la atención de madre e hijo podría ofrecer nuevas oportunidades para educar a los hombres y darles más apoyo en el cuidado de su propia salud y la de su familia.

Palabras clave Padres; esposos; atención prenatal; parto obstétrico; atención posnatal, conocimientos, actitudes y prácticas en salud; El Salvador. 